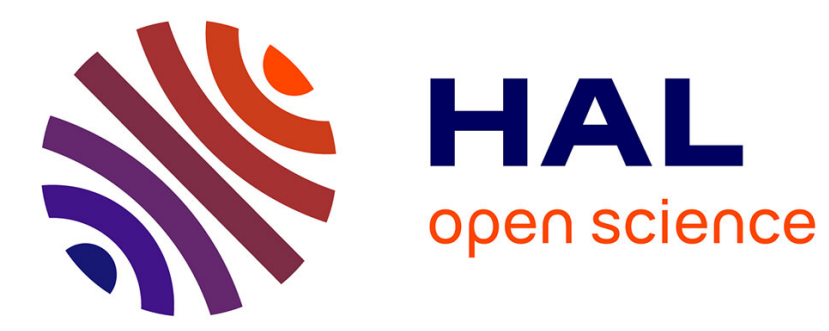

\title{
Derivative based control for LPV system with unknown parameters: An application on a Permanent Magnet Synchronous Motors
}

Sonia Maalej, Alexandre Kruszewski, Romain Delpoux, Lotfi Belkoura

\section{- To cite this version:}

Sonia Maalej, Alexandre Kruszewski, Romain Delpoux, Lotfi Belkoura. Derivative based control for LPV system with unknown parameters: An application on a Permanent Magnet Synchronous Motors. 11th International Multi-Conference on Systems, Signals \& Devices, Feb 2014, Castelldefels-Barcelona, Spain. 10.1109/SSD.2014.6808870 . hal-01248969

\section{HAL Id: hal-01248969 \\ https://inria.hal.science/hal-01248969}

Submitted on 29 Dec 2015

HAL is a multi-disciplinary open access archive for the deposit and dissemination of scientific research documents, whether they are published or not. The documents may come from teaching and research institutions in France or abroad, or from public or private research centers.
L'archive ouverte pluridisciplinaire HAL, est destinée au dépôt et à la diffusion de documents scientifiques de niveau recherche, publiés ou non, émanant des établissements d'enseignement et de recherche français ou étrangers, des laboratoires publics ou privés. 


\title{
Derivative Based Control For LPV System With Unknown Parameters: An Application on a Permanent Magnet Synchronous Motors
}

\author{
Sonia MAALEJ*, Alexandre KRUSZEWSKI ${ }^{\dagger}$, Romain DELPOUX ${ }^{\ddagger}$ and Lotfi BELKOURA* \\ *Non-Asymptotic estimation for online systems \\ INRIA Lille-North Europe, France \\ Laboratoire d'Automatique, Génie Informatique et Signal, \\ CNRS UMR 8219, Université de Lille 1, 59651 Villeneuve d'Ascq, France \\ Email: sonia.maalej@gmail.com \\ $\dagger$ Laboratoire d'Automatique, Génie Informatique et Signal, \\ CNRS UMR 8219, Ecole Centrale de Lille, 59651 Villeneuve d'Ascq, France \\ Email: alexandre.kruszewski@ec-lille.fr \\ †INSM team, Laboratoire des Sciences de l'Information et des Sytèmes, \\ CNRS UMR 7296, 59046 Lille Cedex, France \\ Email: romain.delpoux@ensam.eu
}

\begin{abstract}
This paper deals with the robust stabilization of a class of Linear Parameter Varying (LPV) systems in the continuous time case. Instead of using a state observer or searching for a dynamic output feedback, the controller is based on output derivative estimation. This allows the stabilization of the plant with very large parameter variation and uncertainties. The proof of stability is based on the polytopic representation of the closed loop, Lyapunov conditions and system transformations. The result is a control structure with only few parameters which are tuned via very simple conditions. This paper illustrates the usefulness on real application: Permanent Magnet Synchronous Motors (PMSM) position control.

Index Terms - Linear Time Varying systems, Robust control, Uncertainties, Linear Matrix Inequalities, Polytopic systems, Permanent Magnet Synchronous Motors.
\end{abstract}

\section{INTRODUCTION}

In the industrial process control field, the most common controllers are traditional PID which were developed in 1940s. These controller are very famous because of their low number of tuning parameters allowing in some cases empiric tuning. Unfortunately, due to their linear nature, the performance guarantee are often limited to a statespace region around a given set-point. For complex plants, it is really hard/impossible to tune them correctly without a good model or a more complex control structure. This is due to the nonlinear nature of most systems and the variation of their parameters.

Because internal states of most industrial plants cannot be directly measured and only their outputs are available for control purposes, output feedback controllers were considered. In output feedback design, static output feedback [1], [2], dynamic output feedback [3] and fuzzy observerbased control approaches [4], [5] have been employed. The design procedure of these controller need a good model and for some of them the use of complex optimization techniques. Even if the available model is good enough, using a dynamic model for computing the control law implies the identification of the model parameters. Unfortunately, the choice of the physical model structure, the identification of the model parameters, the experimental validation of model are never simple and are time consuming. Therefore, PID controllers are often tuned with a simple (linear) non physical model $([6],[7])$. However, this could lead to poor results when a process has a large operating domain.

Two important aspects have to be considered in the output feedback control problem. The first one is related to the design of the feedback control law for any system such that the closed loop is stable and guaranteed performances and tracking. This problem has attracted much research effort which resolve this problem by considering for example the $\mathcal{L}_{2}$ gain, $H_{\infty}$ norms (see [8], [9], [10]), robust LQ control [11], [12], [13]. The second one is related to the non availability of all variable parameters in realtime for implementation of complex control laws. As a matter of fact, the control law depends on the output of the system and on some of the varying parameters. If no information about these variable parameters is available, a constant (i.e., independent of the premise variables) output feedback control gain may be an alternative but yielding, in general, conservative results.

A solution to this problem is proposed based on some new results in the framework of model free control given by Cedric et al. [14]. The latter is signal based and don't require many information about the system. To implement this controller, the output derivatives has to be available in real time. In the literature, many variant of such controller have been developed (see [15], [16], [14], [17]). All these 
studies state that the stability as well as performances are ensured but none of them provides a standard proof on a class of system.

There exist in the literature many techniques for the signal derivation. The simplest one is to use a linear derivative filter i.e. any stable transfer function with a stable denominator and a pure differentiators for the numerator. Other possibilities consist in the use of algebraic differentiators [18], [14], Luenberger unknown input observer or sliding mode observers [19], [20], [21], [22].

In this paper, a controller introduced by the authors in previous work [23] is considered. This controller is based on a signal differentiators and dynamic nullification. It has a fixed structure and only one parameter. In order to show the efficiency of this controller, a study case of PMSM (Permanent Magnet Synchronous Motors) position control is given. The stability of the system closed loop under parametric uncertainties is studied using the Lyapunov theory and polytopic transformation. The result is presented as a set of LMI (Linear Matrix Inequalities) to solve.

The first part of this paper describes the class of systems and the controller structure. The second is devoted to the description of the Permanent Magnet Synchronous Motors as well as its polytopic representation. The third part provides numerical LMI solutions ensuring the stability of the controlled PMSM under time varying parametric uncertainties. Some real experiments illustrates the consistency of this approach. The last part gives some conclusions and perspectives.

\section{Problem Formulation}

\section{A. The class of system}

In this paper, we consider the following class of single input single output linear system with time varying parameters:

$y^{(n)}(t)=-a_{0}(t) y(t)-\ldots-a_{n-1}(t) y^{(n-1)}(t)+\alpha u(t)$.

where $y(t) \in \mathbb{R}$ is the output, $u(t) \in \mathbb{R}$ is the control input and $a_{i}$ are scalar time varying parameters.

For design simplification purposes, the system will be viewed as the following equation from the controller point of view:

$$
y^{(v)}(t)=f(t)+\hat{\alpha} u(t) .
$$

It means that only the differential equation order $v$ and an approximation of the parameter $\alpha$ are known. These two parameter are the easiest to get for most real system. In the formulation of the system equation given in $(2), f(t)$ is the function which contains all the dynamic information, i.e. the global dynamic of the system and the possible disturbances. The function $f(t)$ is assumed to be control independent.

Remark 1: $v$ is not necessarily equal to the model order $n$ especially if the model has some fast stable dynamics.

\section{B. The controller}

Since the only information on the system are given by Equation (2), the idea of the controller structure is to nullify the system dynamic $f(t)$ and then replace it with the ideal dynamic for the closed loop. Considering this idea, we get the following controller (Fig. 1):

$$
u(t)=-\frac{1}{\hat{\alpha}}\left(\hat{f}(t)+K \hat{Y}(t)-k_{0} r(t)\right) .
$$

where $\hat{f}(t)$ is the estimate of $f(t), \hat{\alpha}$ is an approximation of $\alpha, r(t)$ is the reference, $\hat{Y}(t)=\left[\begin{array}{lll}z_{0}(t) & \ldots & z_{v-1}(t)\end{array}\right]^{T}$ is a vector composed with $z_{i}(t)$ the estimation of $y^{(i)}(t)$ and $K=\left[\begin{array}{lll}k_{0} & \ldots & k_{v-1}\end{array}\right]$ is a vector with the coefficients of the ideal closed loop dynamic given by the specifications.

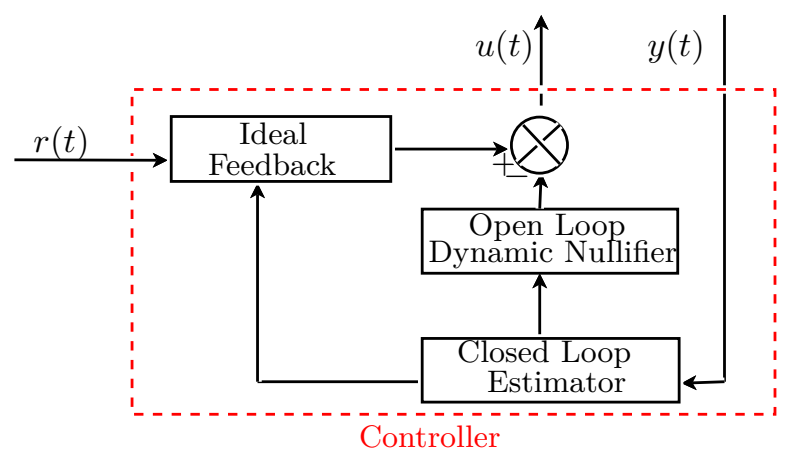

Fig. 1. Controller plant

\section{Derivative estimation}

In this part, the problem of estimation of $f(t)$ and the successive derivatives of $y(t)$ are considered. In order to get a simple solution, we consider linear filters for the output derivation:

$$
\left\{\begin{array}{l}
\frac{z_{0}(s)}{y(s)}=\frac{1}{\tau s+1} \\
\frac{z_{i}(s)}{y(s)}=E(s)^{i}=\left(\frac{s}{\tau s+1}\right)^{i+1} \quad \forall i=1 \ldots v
\end{array}\right.
$$

This estimator is causal and ensures a good estimation if $\tau$ is sufficiently smaller than the fastest relevant dynamic of the system. It provides the successive estimations $z_{i}(t)$ of $y^{(i)}$.

Remark 2: In the literature, many approaches were proposed: one can consider sliding mode estimation [19], [20], [21], [22], Luenberger observer based estimation and algebraic estimation [18].

The estimation of $f(t)$ is made by inverting the dynamic Equation (2) but instead of using the value of $u(t)$, a filtered version of it must be used. This is one of the possible solution to avoid the algebraic loop between $u(t)$ and $\hat{f}(t)$.

$$
\hat{f}(t)=z_{v}(t)-\hat{\alpha} \hat{u}(t)
$$

with $z_{v}(t)$ being the estimation of $y^{(v)}(t)$ and

$$
\frac{\hat{u}(s)}{u(s)}=\frac{1}{\tau s+1} \text {. }
$$




\section{MAIN RESUlT}

Let consider the following model of Permanent Magnet Synchronous Motors (PMSM) in the rotation frame $(d-q)$ [24]:

$$
\left\{\begin{aligned}
L \frac{d i_{d}}{d t} & =v_{d}-R i_{d}+n_{p} L w i_{q} \\
L \frac{d i_{q}}{d t} & =v_{q}-n_{p} L w i_{d}-R i_{q}-K_{c} w \\
J \frac{d w}{d t} & =K_{c} i_{q}-f_{v} w \\
\frac{d \theta}{d t} & =w
\end{aligned}\right.
$$

where $v_{q}$ and $v_{d}$ are the voltages applied to the two phases of the PMSM, $i_{d}$ and $i_{q}$ are the two phase currents, $L$ is the inductance of a phase winding, $R$ is the resistance of a phase winding, $K_{c}$ is the back-EMF constant (and also the torque constant), $w$ is the angular velocity of the rotor, $\theta$ is the angular position of the rotor, $n_{p}$ is the number of pole pairs (or rotor teeth), $J$ is the moment of inertia of the rotor (including the load) and $f_{v}$ is the coefficient of viscous friction.

\section{A. Closed loop State space representation}

The state space representation of the different dynamic equation of the last section are given here. The model in the state space form is given by choosing the state vector as $x_{m}(t)=\left[\begin{array}{lll}i_{d}(t) & i_{q}(t) w(t) \theta(t)\end{array}\right]^{T}, v_{d}=0$ and $v_{q}$ as the system control input and the rotor angular position $\theta(t)$ as output:

$$
\left\{\begin{array}{l}
\dot{x}_{m}(t)=A_{m}(w(t)) x_{m}(t)+B_{m} v_{q}(t) \\
y(t)=C_{m} x_{m}(t)
\end{array}\right.
$$

where

$$
A_{m}(w(t))=\left(\begin{array}{cccc}
-R / L & n_{p} w(t) & 0 & 0 \\
-n_{p} w(t) & -R / L & -K / L & 0 \\
0 & K / J & -f_{v} / J & 0 \\
0 & 0 & 1 & 0
\end{array}\right),
$$

$$
B_{m}^{T}=\left(\begin{array}{llll}
0 & 1 / L & 0 & 0
\end{array}\right) \text { and } C_{m}=\left(\begin{array}{llll}
0 & 0 & 0 & 1
\end{array}\right)
$$

Since the currents dynamics $i_{d}$ and $i_{q}$ are fast and stable, it is sufficient to consider a second order controller design $(v=2)$. The controller (2) is based on the following model:

$$
\begin{array}{ll}
y^{(2)}(t) & =f(t)+\hat{\alpha} u(t) \\
\hat{\alpha} & =\hat{K} /(\hat{J} \hat{R})
\end{array}
$$

The reduced order controller can be represented as it follows where $\dot{x}_{e}(t)=\left[\begin{array}{lll}z_{1}(t) & z_{2}(t) & \hat{\dot{u}}(t)\end{array}\right]^{T}$ :

$$
\left\{\begin{array}{l}
\dot{x}_{e}(t)=A_{e} x_{e}(t)+B_{\text {ey }} y(t)+B_{\text {eu }} v_{q}(t) \\
\hat{Y}(t)=C_{\text {eyx }} x_{e}(t)+C_{\text {eyy }} y(t) \\
\hat{u}(t)=C_{\text {eu }} x_{e}(t)
\end{array}\right.
$$

where:

$$
\begin{gathered}
A_{e}=\left(\begin{array}{ccc}
-\frac{1}{\tau} & 0 & 0 \\
-\frac{1}{\tau^{2}} & -\frac{1}{\tau} & 0 \\
0 & 0 & -\frac{1}{\tau}
\end{array}\right), B_{e u}^{T}=\left(\begin{array}{lll}
0 & 0 & \frac{1}{\tau}
\end{array}\right), \\
C_{e y x}=\left(\begin{array}{ccc}
1 & 0 & 0 \\
-\frac{1}{\tau} & 0 & 0
\end{array}\right), C_{e y y}^{T}=\left(\begin{array}{ll}
0 & \frac{1}{\tau}
\end{array}\right),
\end{gathered}
$$

$$
B_{e y}^{T}=\left(\begin{array}{lll}
\frac{1}{\tau} & \frac{1}{\tau^{2}} & 0
\end{array}\right) \text { and } C_{e u}=\left(\begin{array}{lll}
0 & 0 & 1
\end{array}\right) .
$$

Then, the estimation of the dynamic $f(t)$ is:

$$
\hat{f}(t)=C_{f x} x_{e}(t)+C_{f y} y(t),
$$

where:

$$
C_{f x}=\left(\begin{array}{lll}
-\frac{1}{\tau^{2}} & -\frac{1}{\tau} & -\hat{\alpha}
\end{array}\right) \text { and } C_{f y}=\frac{1}{\tau^{2}} .
$$

By injecting the expression of (3) in (9), the controller can be represented as follows:

$$
\left\{\begin{array}{l}
\dot{x}_{e}(t)=A_{o} x_{e}(t)+B_{o_{1}} y(t)+B_{o_{2}} r(t) \\
v_{q}(t)=C_{o} x_{e}(t)+D_{o_{1}} y(t)+D_{o_{2}} r(t)
\end{array}\right.
$$

where

$$
\begin{aligned}
& A_{o}=A_{e}-\frac{B_{e u}}{\hat{\alpha}}\left(C_{f x}+K C_{e y x}\right) \\
& B_{o_{1}}=B_{e y}-\frac{B_{e u}}{\hat{\alpha}}\left(C_{f y}+K C_{e y y}\right) \\
& B_{o_{2}}=\frac{B_{e u}}{\hat{\alpha}} k_{0} \\
& C_{o}=-\frac{1}{\hat{\hat{\alpha}}}\left(C_{f x}+K C_{e y x}\right) \\
& D_{o_{1}}=-\frac{1}{\hat{\alpha}}\left(C_{f y}+K C_{e y y}\right) \\
& D_{o_{2}}=\frac{k_{0}}{\hat{\alpha}}
\end{aligned}
$$

Finally the closed loop of the system (7) and its controller (10) is:

$$
\left\{\begin{array}{l}
\dot{x}(t)=A(w(t)) x(t)+B r(t) \\
y(t)=C x(t)
\end{array}\right.
$$

with the closed system state $x(t)=\left[x_{m}(t) x_{e}(t)\right]^{T}$,

$$
\begin{gathered}
A(w(t))=\left(\begin{array}{cc}
A_{m}(w(t))+B_{m} D_{o_{1}} C_{m} & B_{m} C_{o} \\
B_{o_{1}} C_{m} & A_{o}
\end{array}\right), \\
B=\left(\begin{array}{c}
B_{m} D_{o_{2}} \\
B_{o_{2}}
\end{array}\right) \text { and } C=\left(\begin{array}{lll}
0_{(1 \times 3)} & 1 & 0_{(1 \times 3)}
\end{array}\right) .
\end{gathered}
$$

Consider that $w(t)$ ranges between known extremal value $w(t) \in[\underline{w}, \bar{w}]$.

In this frame, the PMSM can be described using a LPV state space representation which depends on a time varying parameter $w(t)$.

\section{B. Polytopic representation and stability analysis}

There exist several ways to get stability conditions. Here the closed loop system given by (11) is considered as a polytopic system [25] and the stability analysis is performed using a quadratic Lyapunov function $V(x)=$ $x^{T} P x$. The stability conditions are given in the form of a set of LMI to satisfy.

The model may be represented as follows:

$$
\left\{\begin{aligned}
\dot{x}(t)= & A(\mu(t)) x(t)+B r(t), \\
A(\mu(t))= & \sum_{i=1}^{N} \mu_{i}(t) A_{i}, \forall i, \mu_{i}(t) \geq 0, \\
& \sum_{i=1}^{N} \mu_{i}(t)=1 .
\end{aligned}\right.
$$

where $N=2$, with $A_{1}=A(\underline{w})$ and $A_{2}=A(\bar{w})$.

The stability theorem of this class of system is given by:

Theorem 1: If it exist a matrix $P=P^{T}>0$ such that

$$
A_{i}^{T} P+P A_{i}<0, \quad \forall i=1, \ldots, N
$$


then, the closed loop (12) is asymptotically stable.

The proof is obvious considering the results of [25].

\section{APPLICATION}

In this section, the stability and the robustness of the closed loop is analyzed by considering the stepper motor test bench developed in LAGIS at École Centrale de Lille (see Fig. 3). The motor parameters have been identified in [24]: $R=2.86 \Omega, L=10.2 m H, K_{c}=0.26 N . m . A^{-1}, F_{v}=$

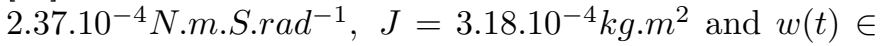
$[-15,15]{\mathrm{rad} . \mathrm{s}^{-1}}^{-}$

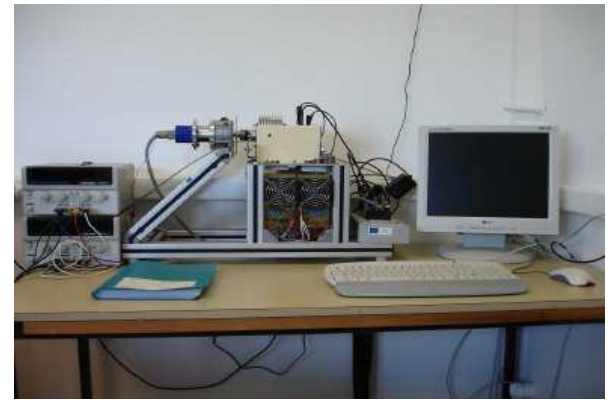

Fig. 3. Stepper-motor test bench.

\section{A. Stability Analysis}

Consider the closed loop (12) with the controller parameters $\tau=0.001, n=2$ and the desired closed loop dynamic $\ddot{y}(t)=-100 y(t)-20 \dot{y}(t)+100 r(t)$ i.e. $K=[10020]$. By using MatLab/SeDuMi [26] as solver and YALMIP [27] as parser in MATLAB $^{\circledR}$, a feasible solution for Theorem 1 LMI conditions is obtained. This ensures the closed loop stability.

\section{B. Experimental result}

The results obtained on the LAGIS test bench (see Fig. 3) are presented in Figure 2. This figure shows the evolution of the PMSM position $\theta(t)$ and the ideal closed loop output $\theta_{\text {ref }}$ (solutions of $\ddot{y}(t)=-k_{0} y(t)-k_{1} \dot{y}(t)+k_{0} r(t)$ ) for different values of $\tau$ and $k_{i}$. It appears clearly that for smaller values of $\tau$ the tracking error $E_{t}$ is closer to zero. Considering small enough $\tau$ allows to follow any specified dynamic $\left(k_{0}, k_{1}\right)$ but the control signal $v_{q}$ is more affected by noises and may be more susceptible to saturate. Despite that the controller is derivative based, the noises affecting the control signal are low and acceptable.
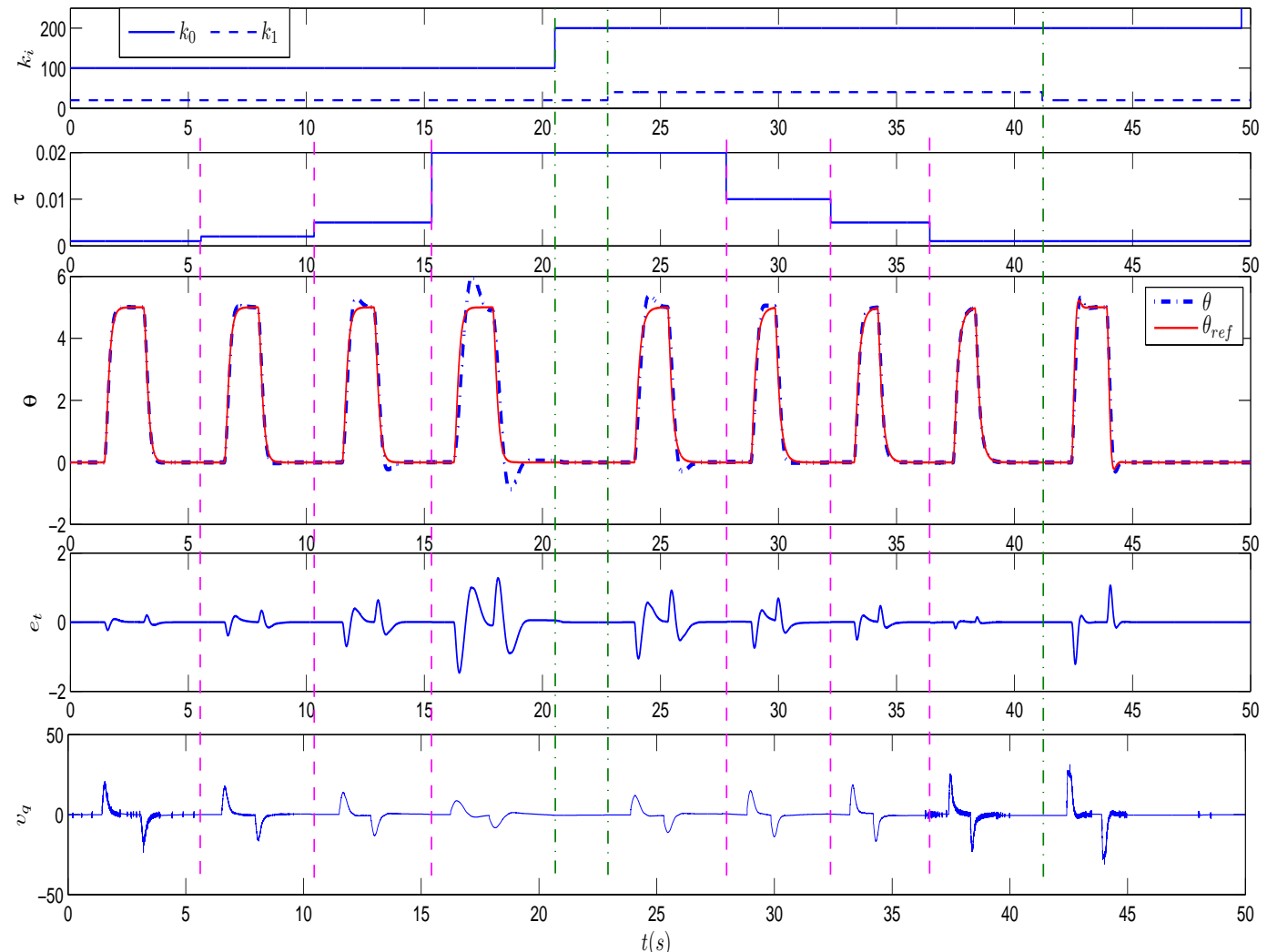

Fig. 2. Experimental results on the PMSM showing the evolution of the output $\theta(t)$, the specified dynamic $\theta_{\text {ref }}(t)$, the tracking error $E_{t}$ and the control signal $v_{q}$ for different value of the controller parameter 


\section{Robustness Analysis}

In order to show the robustness of this controller, we consider two cases: The first case considers time varying uncertainties on the PMSM parameters. The second case considers a bad choice on the controller parameter $\hat{\alpha}$.

\section{A. System Parameters Time Varying Uncertainties}

For this example, consider that the controller parameters are $\tau=0.01, K=\left[\begin{array}{ll}100 & 20\end{array}\right]$ and $\hat{\alpha}=K /(J R)(K, J$ and $R$ being the parameters nominal values). The PMSM parameter (7) uncertainties are now considered with the following system matrix $A_{m}(t)$ :

$$
A_{m}(t)=\left(\begin{array}{cccc}
-p_{3}(t) & n_{p} w(t) & 0 & 0 \\
-n_{p} w(t) & -p_{3}(t) & -p_{4}(t) & 0 \\
0 & p_{1}(t) & -p_{2}(t) & 0 \\
0 & 0 & 1 & 0
\end{array}\right),
$$

where the time varying parameters are:

- $p_{1}(t) \in\left[\begin{array}{ll}0.9 * K / J & 1.2 * K / J\end{array}\right]$ represents the time varying uncertainty on $K / J$,

- $p_{2}(t) \in\left[\begin{array}{ll}0.9 * F_{v} / J & 1.2 * F_{v} / J\end{array}\right]$ represents the time varying uncertainty on $F_{v} / J$,

- $p_{3}(t) \in\left[\begin{array}{ll}R / L & 1.2 * R / L\end{array}\right]$ represents the time varying uncertainty on $R / L$,
- $p_{4}(t) \in\left[\begin{array}{ll}K / L & 1.02 * K / L\end{array}\right]$ represents the time varying uncertainty on $K / L$.

Since the matrix $A_{m}(t)$ is bounded, it is easy to obtain a convex hull vertices [25] $A_{i}, i=1, \ldots, N$ such that $A(t) \in \operatorname{conv}\left(A_{1}, \ldots, A_{N}\right)$. Here $N=2^{5}$ because the matrix $A_{m}(t)$ has 5 independent time varying parameters $(w(t)$ and $\left.p_{i}(t)\right)$. Because the LMI problem of Theorem 1 with these matrices has a feasible solution, then PMSM in closed loop is stable despite the time varying uncertainties.

Note that the results provided here are not optimized. By considering different values of $\tau$ and $\hat{\alpha}$ or by considering more general Lyapunov functions [28], [29], these uncertainties can be considered larger.

\section{B. Bad Tuning Of $\hat{\alpha}$}

For this case, consider that that the controller parameters are $\tau=0.01$ and $K=\left[\begin{array}{ll}100 & 20\end{array}\right]$, and that the parameter $\hat{\alpha}$ has an uncertainty of \pm 20 . By following the same approach as the previous section, the LMI problem of Theorem 1 with the appropriate matrices has a feasible solution so the PMSM in closed loop is stable despite the bad tuning of the parameter $\hat{\alpha}$.

Another important point concerns the system robustness and the estimation of the parameter $\alpha$. Figure 4
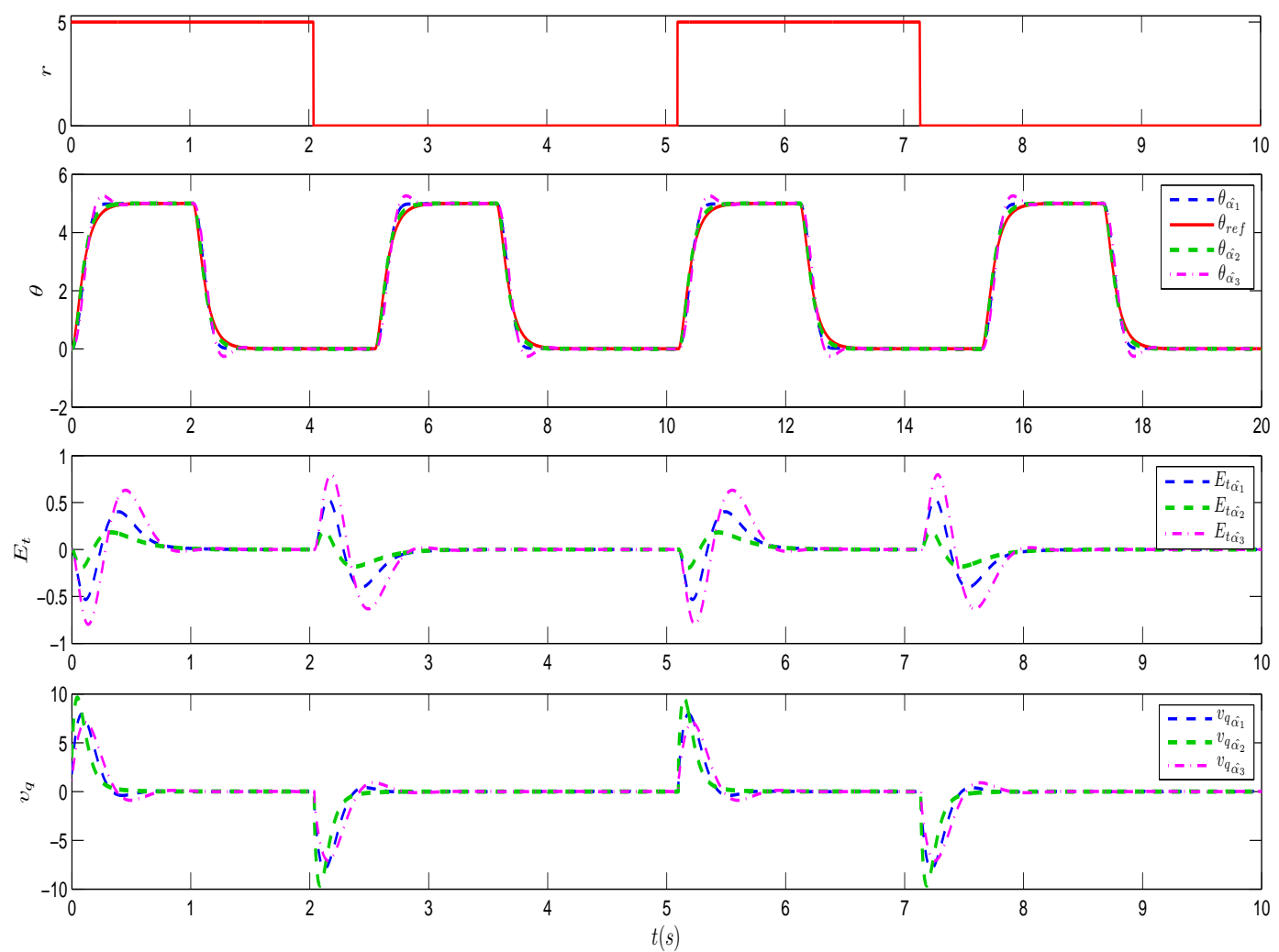

Fig. 4. Simulation results on the PMSM showing the evolution of the output $\theta(t)$, the specified dynamic $\theta_{r e f}(t)$, the tracking error $E_{t}$ and the control signal $v_{q}$ for different approximation of $\alpha$ such that $\hat{\alpha}_{1}=0.5 \alpha, \hat{\alpha}_{2}=\alpha$ and $\hat{\alpha}_{3}=1.5 \alpha$ 
shows that even if there is some mismatch between this parameter and its estimation $\hat{\alpha}$, the stability and the specified dynamic tracking can be guaranteed.

\section{Conclusion}

This paper proposed a method to design dynamic output controller. In contrast of observer based controllers, the proposed controller allows the stabilization of LPV systems even if the time varying parameters are not measured. An application to the Permanent Magnet Synchronous Motors stabilization with uncertainties is proposed. This application shows the good tracking properties of this controller and the simplicity of its tuning. Our future work will deal with extended the class of system (multi-input multi-output, zero dynamics), guaranteed performances and noise rejection.

\section{REFERENCES}

[1] D. Huang and S. K. Nguang, "Static output feedback controller design for fuzzy systems: An ilmi approach," Inf. Sci., vol. 177, no. 14 , pp. 3005-3015, 2007.

[2] B. Mansouri, N. Manamanni, K. Guelton, A. Kruszewski, and T. M. Guerra, "Output feedback lmi tracking control conditions with $h_{\infty}$; criterion for uncertain and disturbed t-s models," Inf. Sci., vol. 179 , no. 4, pp. 446-457, 2009.

[3] M.Sato, "Gain-scheduled output-feedback controllers depending solely on scheduling parameters via parameter-dependent lyapunov functions," Automatica, vol. 12, pp. 2786-2790, 2011.

[4] K. Tanaka, T. Ikeda, and H. Wang, "Fuzzy regulators and fuzzy observers: relaxed stability conditions and lmi-based designs," IEEE Transactions on Fuzzy Systems, vol. 6, no. 2, pp. 250$265,1998$.

[5] A. Sala, T. Guerra, and R. Babuška, "Perspectives of fuzzy systems and control," Fuzzy Sets Syst., vol. 156, no. 3, pp. 432$444,2005$.

[6] K. Åström and T. H. ägglund, Advanced PID Control. ISA - The Instrumentation, Systems, and Automation Society; Research Triangle Park, NC 27709, 2006.

[7] A. Khodabakhshian and M. Edrisi, "A new robust $\{$ PID load frequency controller," Control Engineering Practice, vol. 16, no. 9 , pp. $1069-1080,2008$.

[8] A. Van der Schaft, L2-Gain and Passivity Techniques in Nonlinear Control. Springer, 1996.

[9] B. Zhang and Q. Han, "Robust sliding mode $h_{\infty}$; control using time-varying delayed states for offshore steel jacket platforms," IEEE International Symposium on Industrial Electronics, pp. $1-6,2013$.

[10] S. Li, L. Xiaodong, L. Yong'an, Z. Lilin, and H. Zhengping, "Research on robust $h_{2} / h_{\infty}$; optimization control for unified power quality conditioner in micorgrid," International Power Electronics and Motion Control Conference, vol. 4, pp. 2864$2867,2012$.

[11] Y. Watanabe, I. Takami, and G. Chen, "Tracking control for 2dof helicopter via robust lq control with adaptive law," Control Conference, pp. 399-404, 2012.

[12] Y. Watanabe, N. Katsurayama, I. Takami, and G. Chen, "Robust lq control with adaptive law for mimo descriptor system," Asian Control Conference, pp. 1-6, 2013.

[13] J. Stecha and J. Roubal, "Lq and dead beat control combination from the set of stabilizing controllers," Mediterranean Conference on Control and Automation, pp. 895-900, 2008.

[14] J. Cédric, J. Masse, and M. Fliess, "Étude préliminaire d'une commande sans modèle pour papillon de moteur ..... A modelfree control for an engine throttle: a preliminary study," Journal Européen des Systèmes Automatisés, vol. 42, no. 2-3, pp. 337$354,2008$.
[15] H. Abouaissa, M. Fliess, V. Iordanova, and C. Join, "First steps towards a model-free control of a freeway traffic flowProlégomènes à une régulation sans modèle du trafic autoroutier," Conférence Méditerranéenne sur l'Ingénierie Sûre des Systèmes Complexes, 2011.

[16] P. Gédouin, E. Delaleau, J. Bourgeot, C. Join, S. Arbab-Chirani, and S. Calloch, "Experimental comparison of classical pid and model-free control: position control of a shape memory alloy active spring," May 2011.

[17] B. D. Novel, C. Boussard, M. Fliess, O. E. Hamzaoui, H. Mounier, and B. Steux, "Commande sans modèle de la vitesse longitudinale d'un véhicule électrique," in Sixième Conférence Internationale Francophone d'Automatique, 2010.

[18] M. Mboup, "Parameter estimation for signals described by differential equations," Applicable Analysis, vol. 88, no. 1, pp. $29-52,2009$

[19] J. Slotine, "Sliding controller design for non-linear systems," International Journal of Control, vol. 40, no. 2, pp. 421-434, 1984.

[20] M. N. Nounou, H. N. Nounou, and M. S. Mahmoud, "Robust adaptive sliding-mode control for continuous time-delay systems," IMA Journal of Mathematical Control and Information, vol. 24, no. 3, pp. 299-313, 2007.

[21] X. Yan, S. Spurgeon, and C. Edwards, "Robust sliding mode observer with parameters estimation for a class of nonlinear timedelay systems," IEEE Conference on Decision and Control, pp. $96-101,2010$.

[22] Y. Feng and L. Wang, "Terminal sliding mode observer based parameter estimation method for permanent magnet synchronous motor control system," International Workshop on Variable Structure Systems, pp. 184-189, 2010.

[23] S. Maalej, A. Kruszewski, and L. Belkoura, "Derivative based control for ltv system with unknown parameters," European Control Conference, 2013.

[24] R. Delpoux, M. Bodson, and T. Floquet, "Parameter estimation of permanent magnet stepper motors without position or velocity sensors," in American Control Conference, 2012.

[25] E. F. S. Boyd, L. El-Ghaoui and V. Balakrishnan, "Linear matrix inequalities in system and control theory," SIAM, vol. 15, pp. 23-24, 1994

[26] J. F. Sturm, "Using sedumi 1.02, a matlab toolbox for optimization over symmetric cones," Optimization Methods and Software, vol. 11, no. 1-4, pp. 625-653, 1999.

[27] J. Lofberg, "Yalmip : a toolbox for modeling and optimization in matlab," IEEE International Symposium on Computer Aided Control Systems Design, pp. 284-289, 2004.

[28] M. Asemani, V. Majd, and S. Mobayen, "A multiple lyapunov function approach for robust $h_{\infty}$; observer-based tracking control of uncertain t-s fuzzy systems," International Conference on Control, Instrumentation and Automation, pp. 367-372, 2011.

[29] W.-R. Horng, C.-H. Fang, C.-H. Lee, and J.-H. Chou "H2 guaranteed cost of uncertain continuous t-s fuzzy systems by multiple lyapunov function approach," IEEE International Conference on Fuzzy Systems, pp. 1380-1387, 2011. 